\title{
Ispitivanje ispravnosti automatskih mernih sistema za kontinualno merenje emisije u TE Nikola Tesla A na bloku A6 u periodu od 2012. do 2016. godine
}

T "ermoelektrana „Nikola Tesla A“, smeštena na desnoj obali Save nadomak Obrenovca, predstavlja najveću termoelektranu u Srbiji, sa šest blokova, instalisane snage 1.650 MWel. U okviru IPA 2008 programa Evropske komisije pod nazivom „Equipment for Continuous Emissions Monitoring System at Electric Power Industry of Serbia (EPS) - TENT“, u termoelektranama „Nikola Tesla A“, „Nikola Tesla B“ i „Kolubara“ tokom 2011. i 2012. godine uvedeno je kontinualno merenje emisije zagađujućih materija u vazduh. Kontinualno merenje emsije vrši se automatskim mernim sistemom (AMS) kojim se osiguravaju podaci o koncentraciji i masenom protoku zagađujuće materije $\mathrm{u}$ otpadnom gasu tokom neprekidnog rada postrojenja [1].

\section{Uvod}

U TE „Nikola Tesla A“ na bloku A6 kontinualnim merenjem obuhvaćene su glavne zagađujuće materije: sumpor dioksid $\left(\mathrm{SO}_{2}\right)$, ugljen monoksid $(\mathrm{CO})$, oksidi azota $\left(\mathrm{NO}_{\mathrm{x}}\right)$ i praškaste materije. Radi vrednovanja i ocene kontinualnog merenja uvedeno je i merenje tzv. perifernih parametara, odnosno parametara stanja otpadnog gasa: temperature, pritiska, zapreminskog protoka, sadržaja vlage i sadržaja kiseonika $\left(\mathrm{O}_{2}\right)$.

Uredbom o graničnim vrednostima emisija zagađujućih materija u vazduh iz postrojenja za sagorevanje [2] definisana je najveća dozvoljena količina zagađujuće materije sadržana u otpadnom gasu koja može biti emitovana u vazduh (GVE - granična vrednost emisije). U cilju poređenja sa graničnim vrednostima emisije, rezultati merenja izraženi kao masena koncentracija zagađujućih materija u otpadnom gasu preračunavaju se na jedinicu zapremine suvih otpadnih gasova, normalne uslove (temperatura 273,15 K i pritisak 101,3 $\mathrm{kPa}$ ) i referentni udeo kiseonika u otpadnom gasu, koji za postrojenja za sagorevanje čvrstog goriva iznosi $6 \%$.

\section{SRPS EN 14181 - Obezbeđenje kvaliteta au- tomatskih mernih sistema}

$\mathrm{Za}$ trajno ugrađene automatske merne sisteme (AMS) na stacionarnim izvorima zagađenja, Evropska direktiva o industrijskim emisijama IED [3] zahteva obezbeđenje kvaliteta u skladu sa Evropskom normom EN 14181 [4]. Uspostavljaju se tri nivoa kvaliteta AMS (QAL1, QAL2 i QAL3) kojima se definišu postupci za ispunjavanje zahteva za sertifikaciju, verifikaciju, kalibraciju i stalnu proveru AMS tokom njegovog rada, kao i zahteva za mernu nesigurost koja je definisana zakonskom regulativom. Kao dodatni četvrti nivo propisan je godišnji kontrolni test (AST - annual surveillance test) $\mathrm{u}$ cilju provere performansi, varijabilnosti i validnosti kalibracione funkcije AMS-a. Za obezbeđenje kvaliteta AMS-a za praškaste materije CEN je izdao i standard EN 13284-2 [5] koji se poziva na EN 14181 i primenjuje se samo u skladu sa njim.

\subsection{QAL1 - Obezbeđenje poverenja nivoa 1}

Postupak za obezbeđenje poverenja nivoa 1 (QAL1) se koristi da bi se pokazala potencijalna podobnost AMS-a pre nego što se postavi na merno mesto. AMS mora da zadovolji zahteve standarda SRPS EN ISO 14956 [6] i SRPS EN 15267-3 [7] u kojima su definisani postupci koji obuhvataju zahteve QAL1 standarda SRPS EN 14181. Korišćenjem ovih standarda potrebno je dokazati da ukupna merna nesigurnost dobijenih rezultata zadovoljava zahteve propisane zakonskom regulativom [1], [3].

Ako je instrument testiran na odgovarajući način u skladu sa SRPS EN 15267-3 onda se može smatrati da automatski ispunjava zahteve QAL1 (sve dok delokrug testova standarda SRPS EN 15267-3 potvrđuje da je instrument odgovarajući za tip procesa na odredišnom postrojenju). U tim slučajevima rezultati QAL1 koji prate sertifikaciju AMS-a mogu da se koriste bez daljih proračuna i predstavljaju ulazne podatke za obezbeđenje poverenja nivoa 3 (QAL3). Ako takvi podaci nisu raspoloživi za određeni AMS oni se mogu zameniti podacima koji su dati u proizvođačkim specifikacijama sličnih AMS-a.

\subsection{QAL2 - Obezbeđenje poverenja nivoa 2}

Kalibracija AMS se vrši u skladu sa procedurom obezbeđenja poverenja nivoa 2 (QAL2) koja je data standardom SRPS EN 14181. Procedura obuhvata seriju paralelnih merenja (najmanje 15) sa standardnim referentnim metodama (SRM). Određuje se kalibraciona funkcija na osnovu SRM i AMS dobijenih rezultata i definiše se validni opseg kalibracije, a zatim se sprovodi test varijabilnosti AMS vrednosti radi provere usaglašenosti sa zahtevanom mernom nesigurnošću. Pre sprovođenja QAL2 neophodno je da AMS bude postavljen na reprezentativnom mernom mestu, u skladu sa SRPS EN 15259 [8].

Kalibracija AMS vrši se najmanje jednom u 5 godina, a u slučaju neke značajne promene u funkcionisanju postrojenja ili intervencije na AMS koja može imati uticaj na pouzdanost rezultata, QAL2 je neophodno sprovesti u periodu od 6 meseci od tih promena. 
Zahtev standarda SRPS EN 14181 je da se u sklopu QAL2 i AST jednom godišnje sprovodi. test funkcionalnosti. Testove sprovodi kompetentna akreditovana laboratorija sa dozvolom nadležnog ministarstva, najviše 30 dana pre paralelnih merenja u okviru QAL2 i AST. Cilj je da se kroz seriju provera pokaže da AMS ispunjava propisane zahteve i da je funkcionalno spreman za paralelna merenja. U Tabeli 1 prikazane su pojedinačne provere u okviru funkcionalnog testa za ekstraktivni i ne-ekstraktivni AMS. Standard SRPS EN 15267-3 propisuje procedure ovih testova i provera AMS.

Tabela 1. Testovi funkcionalnosti AMS

\begin{tabular}{|l|c|c|}
\hline Test & Ekstraktivni AMS & $\begin{array}{c}\text { Ne-ekstraktivni } \\
\text { AMS }\end{array}$ \\
\hline Poravnanje i čistoća & & $\sqrt{ }$ \\
\hline Sistem za uzorkovanje & $\sqrt{ }$ & \\
\hline Dokumentacija i zapisi & $\sqrt{ }$ & $\sqrt{ }$ \\
\hline Opsluživanje & $\sqrt{ }$ & $\sqrt{ }$ \\
\hline Test zaptivenosti & $\sqrt{ }$ & \\
\hline Provera nule i“span”-a & $\sqrt{ }$ \\
\hline Linearnost & $\sqrt{ }$ & $\sqrt{ }$ \\
\hline Smetnje & $\sqrt{ }$ & $\sqrt{ }$ \\
\hline Vreme odziva & $\sqrt{ }$ & $\sqrt{ }$ \\
\hline
\end{tabular}

Pored kalibracije automatskih mernih sistema koji mere koncentracije zagađujućih materija za koje je propisano kontinualno merenje zakonskom regulativom, preporuka je da se u okviru QAL2 vrši i kalibracija tzv. perifernih AMS. Periferni parametri (sadržaj kiseonika, sadržaj valge, temperatura i pritisak otpadnog gasa) su neophodni za svođenje merenih vrednosti na standardne uslove.

\subsection{Godišnji kontrolni test (AST)}

Godišnji kontrolni test (AST) ima za cilj proveru varijabilnosti i validnosti kalibracione funkcije određene u okviru QAL2. Takođe, svrha AST je da pokaže da merna oprema funkcioniše ispravno i da njene performanse i dalje ispunjavaju zahtevane kriterijume. Test funkcionalnosti se sprovodi na isti način kao za QAL2 od strane akreditovane, i od nadležnog ministarstva ovlašćene laboratorije. AST test obuhvata najmanje 5 paralelnih merenja SRM-AMS. Procedura za sprovođenje paralelnih merenja je ista kao za QAL2.

\subsection{QAL3 - Obezbeđenje poverenja nivoa 3}

Nakon sertifikacije (QAL1) i kalibracije (QAL2), neophodno je sprovoditi stalnu kontrolu kvaliteta AMS-a (QAL3). Tokom svog rada AMS može početi da odstupa i postati manje precizan. Ta nestabilnost može biti izazvana kontaminacijama na samom AMS (zaprljanost optike (sočiva), zapušenost filtera, itd.), što izaziva sistematsko odstupanje. Sa druge strane, AMS je podložan kratkotrajnim varijacijama u stabilnosti i preciznosti pod uticajem faktora kao što su promene u ambijentalnoj temperaturi i pritisku. Te varijacije izazivaju tzv. slučajno odstupanje, koje do nekog stepena može biti prihvatljivo. Stoga, QAL3 zahteva sprovođenje procedure koja obuhvata:

- merenje (provera) nulte i "span” vrednosti;

- $\quad$ izradu kontrolnih karata;
- $\quad$ propisivanje granica upozorenja i granica akcije na kontorlnim kartama, odnosno propisivanje kriterijuma kada je potrebno pokrenuti korektivne mere za otklanjanje neprihvatljivih odstupanja.

Kontrolne karte zahtevaju redovne i idealno učestale provere. Redovna merenja na nultoj i referentnoj tački ("span”) predstavljaju osnov QAL3 procedure. Učestalost provere AMS u okviru QAL3 procedure je definisana da bude jednom u toku intervala održavanja. Interval održavanja određuje se tokom sertifikacije AMS-a (QAL1) prema SRPS EN 15267-3. Na osnovu kontrolnih karata može se pratiti trend merenih vrednosti i uvideti kada je neophodno podešavanje AMS-a. Takođe obaveza operatera je da obezbedi da AMS radi u okviru validnog kalibracionom opsega.

\section{Automatski merni sistemi za kontinualno mernje emisije na bloku A6}

\subsection{AMS za praškaste materije}

U TE „Nikola Tesla A“ na bloku A6 za kontinualno merenje emisje praškasih materija instaliran je optički uređaj DR-290, Durag $\mathrm{GmbH}$, koji se sastoji od optičke jedinice (primopredajnik), reflektora, kontrolne jedinice i kompresora za vazdušno čišćenje. Uređaj meri slabljenje inteziteta emitovane svetlosti kroz optički put usled interakcije zračenja sa praškastim materijama u otpadnom gasu. Fizička veličina koju uređaj meri je transparencija, odnosno odnos inteziteta početnog i reflektovanog zračenja. Iz transparencije izračunava se ekstinkcija kao negativan logaritam transparencije. Parametrizacija uređaja vrši se preko kontrolne jedinice.

\subsection{AMS za CO, NOX i SO2}

AMS za gasovite polutatnte $\left(\mathrm{CO}, \mathrm{NO}_{\mathrm{X}}\right.$ i $\left.\mathrm{SO}_{2}\right)$ se sastoji od sonde za uzorkovanje, grejane linije za transport uzorka, sistema za kondicioniranje otpadnog gasa i gasnog analizator Ultramat 23, Siemens. Osim glavnih zagađujućih materija analizator meri i zapreminske udele kiseonika $\left(\mathrm{O}_{2}\right)$ i ugljen dioksida $\left(\mathrm{CO}_{2}\right)$, radi svođenja rezultata merenja na referentne uslove. Merna tehnika gasnog analizatora za $\mathrm{CO}, \mathrm{NO}_{\mathrm{X}}, \mathrm{SO}_{2} \mathrm{i} \mathrm{CO}_{2}$ je nedisperzivna infracrvena spektrometrija (NDIR), dok se za određivanje zapreminskog udela kiseonika koristi elektrohemijski senzor (EC).

\section{$4 \quad$ SRM metode}

\subsection{SRM za praškaste materije}

AMS za praškaste materije ne meri direktno koncentraciju praškastih materija već određenu fizičku veličinu, pa je direktna kalibracija referentnim materijalom neizvodljiva. S toga se kalibracija vrši direktnim poređenjem AMS vrednosti sa rezultatima dobijenim standardnom referentnom metodom (SRM), što je u slučaju praškastih materija manualna gravimetrijska metoda: SRPS EN 13284-1 [9] i SRPS ISO 9096 [10].

Merenje koncentracija praškastih materija stantardnom referentnom metodom (SRM) vršeno je izokinetički u mernoj ravni kvadratnog poprečnog preseka $(5 \mathrm{~m}$ x $5 \mathrm{~m})$ u 20 definisanih mernih tačaka. Merna ravan se nalazi na dimnom kanalu posle elektrostatičkog fil- 


\section{PT Tema broja}

tera $\mathrm{i}$ ventilatora dimnog gasa $\mathrm{i}$ ima pet mernih otvora. Kao i kod svake gravimetrijske metoda, koncentracija praškastih materija se izračunava na osnovu razlika masa pre i posle merenja (masa filtera i masa čestica prašine $u$ rastvoru od ispiranja delova uzvodno od filtera) i zapremine uzorkovanog otpadnog gasa. Šema aparature za uzorkovanje prikazana je na Slici 1.

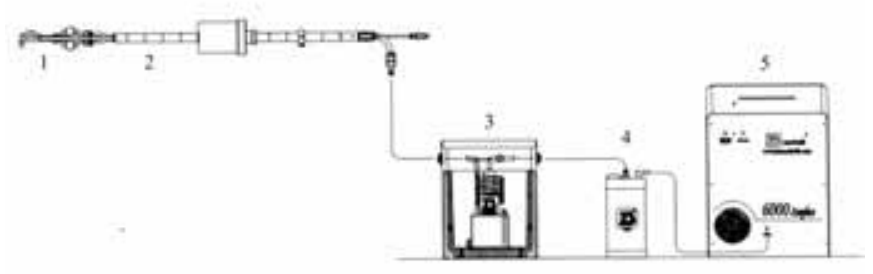

Slika 1: Šema aparature za izokinetičko uzorkovanje praškastih materija (1-mlaznica sa filterom i S Pito cev, 2-sonda, 3-hladnjak sa kondenzatorom, 4-silika gel, 5-automatski izokinetički uzorkivač)

\subsection{SRM za CO, $\mathrm{NO}_{x}$ i SO}

Masene koncentracije ugljen monoksida (CO) i oksida azota $\left(\mathrm{NO}_{\mathrm{X}}\right)$ merene su automatskim metodama gasnim analizatorom PG250, Horiba. Standardna referentna metoda za određivanje masene koncentracije ugljen monoskida jeste metoda SRPS EN 15058 [11] čija je merna tehnika nedisperzivna infracrvena spektrometrija (NDIR), dok za određivanje masene koncentracije oksida azota $\left(\mathrm{NO}_{\mathrm{X}}\right)$, SRM metoda SRPS EN 14792 [12] primenjuje hemiluminisenciju (CLS) kao mernu tehniku. Merna aparatura se sastoji od grejane sonde za uzorkovanje, grejane linije, kondicionera otpadnog gasa i gasnog analizatora. Akvizicija podataka vrši se preko integrisanog data logera.

Standardna referenta metoda za određivanje masene koncentracija SO2 je metoda SRPS EN 14791 [13] koja opisuje manuelno uzorkovanje i određivanje sadržaja SO2 torinskom analitičkom metodom. Aparaturu za uzorkovanje čine grejana sonda sa grejanim filterom, grejane linije, dve ispiralice sa apsorpcionim rastvorom $\left(0,3 \%\right.$ vodonik-peroksid $\left.\mathrm{H}_{2} \mathrm{O}_{2}\right)$, silika gelom, pumpom, rotametrom, gasnim satom sa merenjim temperature i pritiska (Slika 2).

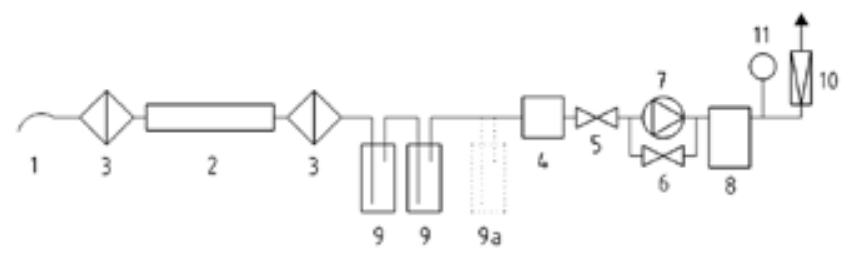

Slika 2: Šema aparature za uzorkovanje $\mathrm{SO}_{2}$ (1-mlaznica, 2-sonda, 3-filter, 4-silika gel, 5-ventil, 6-by-pass ventil, 7-pumpa, 8-gasni sat, 9-ispiralice, 10-rotametar, 11-merač temperature i pritiska)

\section{$5 \quad$ Rezultati ispitivanja}

Inicijalna kalibracija (QAL2 procedura) za navedene parametre izvršena je u aprilu 2012. godine. Izvršeno je po 16 uporednih merenja na osnovu kojih su određene kalibracione funkcije i izvršen test varijabilnosti.

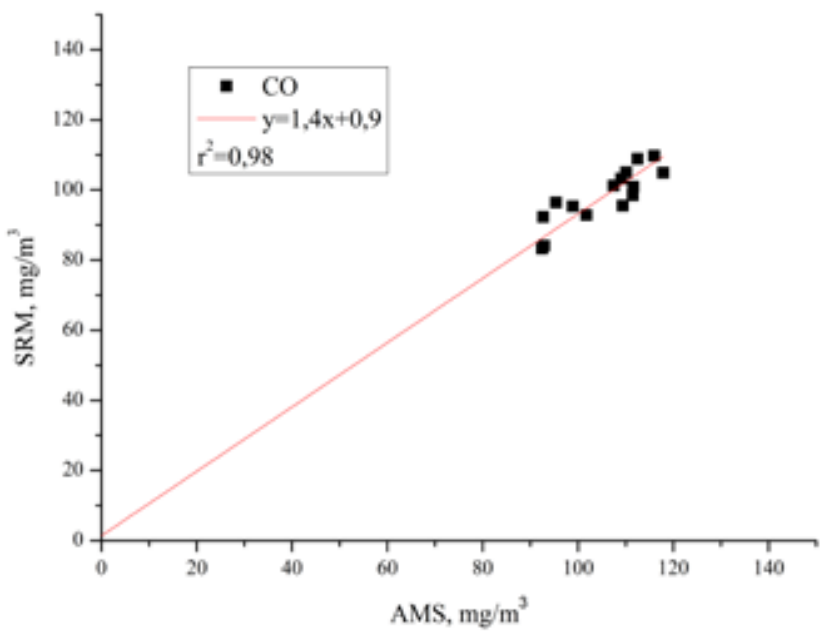

Slika 3: Kalibraciona funkcija za ugljen monoksid (CO) na bloku A6

\subsection{Ugljen monoksid (CO)}

Kalibraciona funkcija u obliku $y=1,4 x+0,9$ prikazana je grafički na Slici 3. Granična vrednost emisije (GVE) i 95\% interval poverenja (CI), koji su neophodi podaci za određivanje kalibracione funkcije i sprovođenje testa varijabilnosti, definisani su zakonskom regulativom. Za ugljen monoksid, prema Uredbi o graničnim vrednostima emisije zagađujućih materija u vazduh iz postrojenja za sagorevanje [2] i Uredbi o merenjima emsija zagađujućih materija u vazduh iz stacionarnih izvora zagađivanja [1], pomenute vrednosti iznose: $\mathrm{GVE}=250 \mathrm{mg} / \mathrm{m}^{3}$ i $\mathrm{CI}=10 \%$. Postupak sprovođenja QAL2 procedure definisan u standardu SRPS EN 14181.

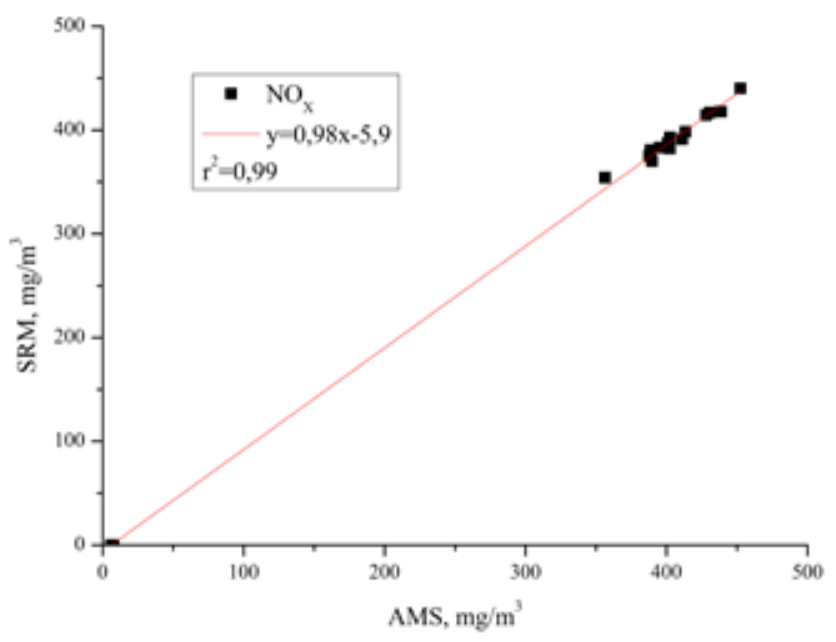

Slika 4: Kalibraciona funkcija za okside azota $\left(\mathrm{NO}_{\mathrm{X}}\right)$ na bloku A6 


\subsection{Oksidi azota $\left(\mathrm{NO}_{\mathrm{x}}\right)$}

Kalibraciona funkcija u obliku $y=0,98 x-5,9$ prikazana je grafički na Slici 4. granična vrednost emisije (GVE) i 95\% interval poverenja (CI) iznose: $\mathrm{GVE}=500 \mathrm{mg} / \mathrm{m}^{3}$ i $\mathrm{CI}=20 \%$.

\subsection{Sumpor dioksid $\left(\mathrm{SO}_{2}\right)$}

Kalibraciona funkcija u obliku $\mathrm{y}=1,0 \mathrm{x}+7,0$ prikazana je grafički na Slici 5. Granična vrednost emisije (GVE) i 95\% interval poverenja (CI) iznose: $\mathrm{GVE}=400 \mathrm{mg} / \mathrm{m}^{3}$ i $\mathrm{CI}=20 \%$.

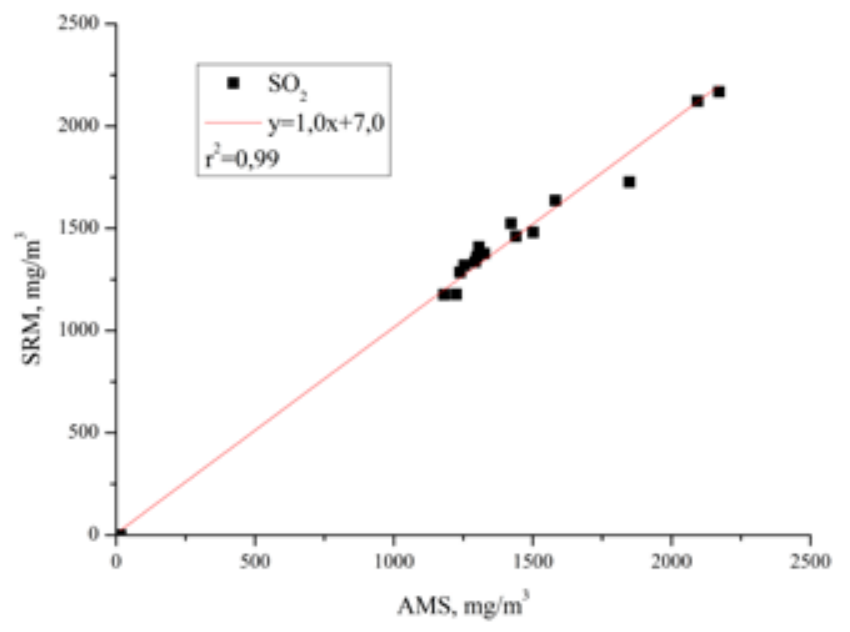

Slika 5: Kalibraciona funkcija za sumpor dioksid $\left(\mathrm{SO}_{2}\right)$ na bloku A6

\subsection{Praškaste materije}

Kalibraciona funkcija $\mathrm{u}$ obliku $\mathrm{y}=35,9 \mathrm{x}+0,36$ prikazana je grafički na Slici 6. Granična vrednost emisije (GVE) i 95\% interval poverenja (CI) iznose: $\mathrm{GVE}=50 \mathrm{mg} / \mathrm{m}^{3}$ i $\mathrm{CI}=300 \%$.

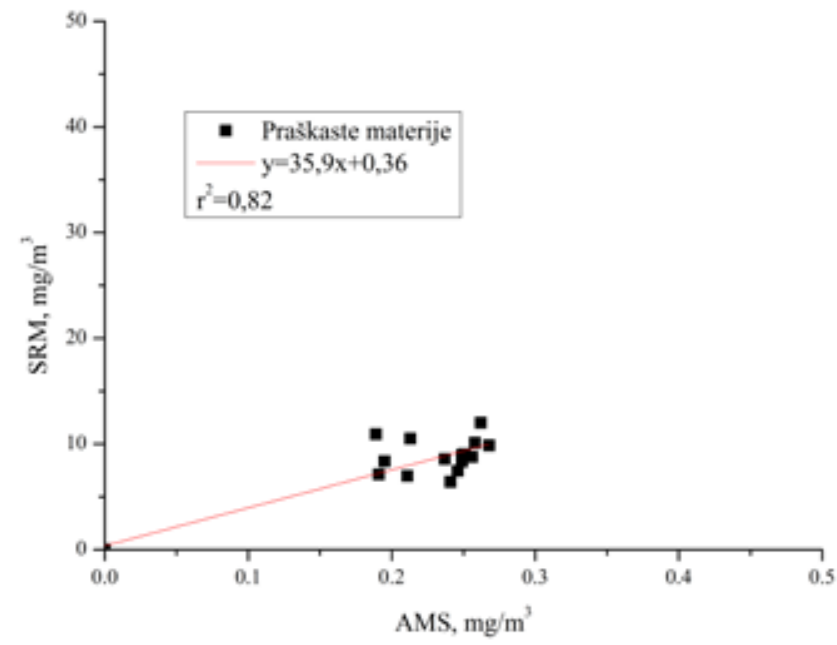

Slika 6: Kalibraciona funkcija za praškaste materije na bloku A6

Na Slici 6 može se primetiti da je koeficijent korelacije $r 2=0,82$ manji od 0,9. Koeficijent korelacije nije obavezujući kriterijum koji se mora ispuniti, ali vrednost veća od 0,9 predstavlja dobar indi- kator o validnosti kalibracione funkcije. Vrednost $r 2<0,9$ ne znači automatski da QAL2 nije uspešno sproveden, već test varijabilnosti predstavnja krajnju indikaciju uspešnosti [14]. U ovom slučaju kalibraciona funkcija je prošla test varijabilnosti uprkos manjoj vrednosti koeficijenta korelacije od 0,9 .

\section{$6 \quad$ Zaključak}

Tokom 2012. godine u TE „Nikola Tesla A“ na bloku A6, uspešno su implementirani automatski merni sistemi za kontinualno merenje emisije zagađujućih materija u vazduh. Obezbeđenje kvaliteta AMS-a u skladu sa SRPS EN 14181 otvorilo je novo poglavlje monitoringa emisije zagađujućih materija u vazduh u termoelekranama u Srbiji. Kontinualno merenje emisije postalo je obaveza zahtevana evropskom i nacionalnom regulativom, naročito za velike stacionarne izvore zagađivanja.

Sprovedena QAL2 procedura od strane Laboratorije za zaštitu životne i radne sredine Rudarskog instituta, potvrdila je ispravnost i funkcionalnost automatskih mernih sistema. Tokom naredne četiri godine sprovođeni su AST testovi koji su potvrdili varijabilnost i validnost kalibracionih funkcija, kao i da je preciznost AMS i dalje u zahevanim okvirima, odnosno da AMS vrednosti i dalje isunjavaju zahteve za mernu nesigurnost koji su definisani zakonskom regulativom.

\section{Literatura}

[1] Uredba o merenjima emisija zagađujućih materija $u$ vazduh iz stacionarnih izvora zagađivanja, Službeni glasnik Republike Srbije 5/16, 2016.;

[2] Uredba o graničnim vrednostima emisija zagađujućih materija $u$ vazduh iz postrojenja za sagorevanje, Službeni glasnik Republike Srbije 6/16, 2016;

[3] Directive 2010/75/EU of the European Parliament and of the Council of 24 November 2010 on Industrial Emissions (Integrated Pollution Prevention and Control), European Commission, 2010;

[4] SRPS EN 14181:2015, Emisije iz stacionarnih izvora Obezbeđenje kvaliteta automatskih mernih Sistema, Institut za standardizaciju Srbije, 2015;

[5] SRPS EN 13284-2:2009, Emisije iz stacionarnih izvora Određivanje prašine u opsegu niskih masenih koncentracija - Deo 2: Automatizovani merni sistemi, Institut za standardizaciju Srbije, 2009;

[6] SRPS EN ISO 14956:2010, Kvalitet vazduha - Vrednovanje pogodnosti merne procedure poređenjem sa zahtevanom mernom nesigurnošću, Institut za standardizaciju Srbije, 2010;

[7] SRPS EN 15267-3:2010, Kvalitet vazduha - Sertifikacija automatizovanih mernih sistema - Deo 3: Kriterijumi za performanse i procedure ispitivanja automatizovanih mernih sisitema za monitoring emisije iz stacionarnih izvora, Institut za standardizaciju Srbije, 2010;

[8] SRPS EN 15259:2010, Kvalitet vazduha - Merenje emisije iz stacionarnih izvora - Zahtevi za merne preseke $i$ ravni $i$ za ciljeve merenja, planiranje i izveštavanje, Institut za standardizaciju Srbije, 2010;

[9] SRPS EN 13284-1:2009, Emisije iz stacionarnih izvora - 
Određivanje prašine u opsegu niskih masenih koncentracija - Deo 1: Manuelna gravimetrijska metoda, Institut za standardizaciju Srbije, 2009;

[10] SRPS ISO 9096:2010, Emisije iz stacionarnih izvora - Manuelno određivanje masene koncentracije praškastih materija, Institut za standardizaciju Srbije, 2010;

[11] SRPS EN 15058:2009, Emisije iz stacionarnih izvora Određivanje masene koncentracije ugljen-monoksida (CO) - Referentna metoda: nedisperzivna infracrvena spektrometrija, Institut za standardizaciju Srbije, 2009;

[12] SRPS EN 14792:2009, Emisije iz stacionarnih izvora Određivanje masene koncentracije oksida azota $\left(N O_{X}\right)$ - Referentna metoda: hemiluminiscencija, Institut za standardizaciju Srbije, 2009; [13] SRPS EN 14791:2009, Emisije iz stacionarnih izvora Određivanje masene koncentracije sumpordioksida - Referentna metoda, Institut za standardizaciju Srbije, 2009;

[14] Technical Guidance Note M20, Quality assurance of continuous emission monitoring systems - application of EN 14181 and BS EN 13284-2, Envaironment Agency UK, 2015.

\section{Autor}

Marko PAVLOVIĆ

Rudarski institut d.o.o.

Batajnički put 2, 11080 Beograd

marko.pavlovic@ribeograd.ac.rs

\section{Mihajlo GIGOV}

Rudarski institut d.o.o.

Batajnički put 2, 11080 Beograd

\section{Sandra PETKOVIĆ}

Rudarski institut d.o.o.

Batajnički put 2, 11080 Beograd

Miroslav SOFRENIĆ

Rudarski institut d.o.o.

Batajnički put 2, 11080 Beograd

\section{Izdanja SMEITS-a}

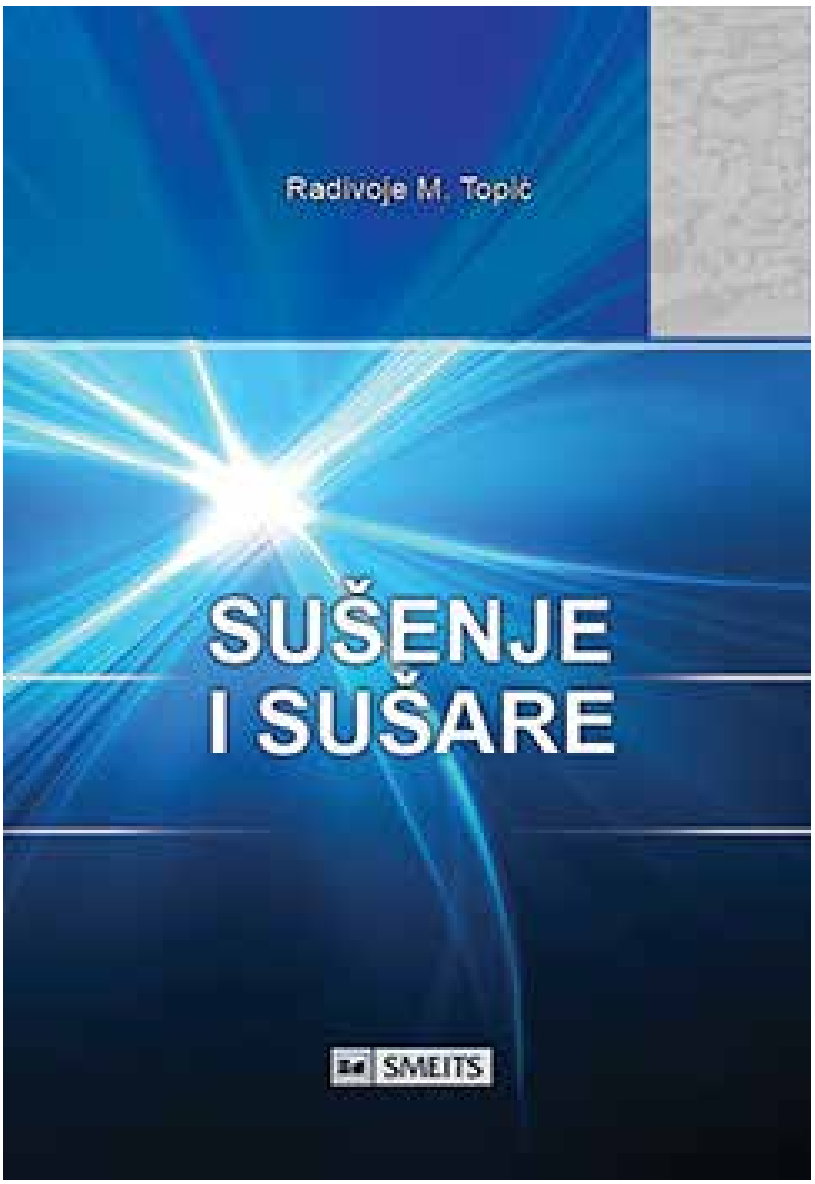

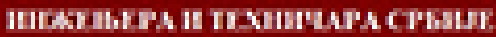

BROIIOMCKE ALAIHS 3 IIOTPEHE IIPOULCIOГ IIIAEПLPCTDA 